\title{
Four Decades of Trauma: Blood, Sweat, and Tears
}

\author{
Rao Ivatury
}

\section{Abstract}

This report is a personal reflection on four decades of trauma, remembering legends of the past, focusing on the metamorphosis of trauma surgery, and speculating on its future.

Keywords: Acute care surgery, Emergency general surgery, Intensive care, Trauma.

\section{Resumo}

Este artigo é uma reflexão pessoal sobre quatro décadas de trauma, lembrando personalidades e lendas do passado, enfocando a metamorfose da cirurgia do trauma e especulando sobre seu futuro.

Palavras-chave: Cirurgia Geral de Emergência, Trauma, Terapia Intensiva.

Panamerican Journal of Trauma, Critical Care \& Emergency Surgery (2020): 10.5005/jp-journals-10030-1273

\section{INTRODUCTION}

The author had the great privilege of enjoying a career in general surgery before his retirement a few years ago. Starting in general surgery, the career morphed into a specialization in trauma and surgical intensive care, a career built on blood, sweat, and tears. Finally it was "back to the future" to acute care surgery and elective general surgery. This report is a personal reflection on this experience, remembering legends of the past, focusing on the metamorphosis of trauma surgery, and speculating on its future.

\section{New York City Blackout}

It was the summer of 1977. A hot and humid July 13 at around 9:30 p.m. Lightning strikes a Consolidated Edison substation along the Hudson River, tripping two circuit breakers and setting off a chain of events. The result was a massive power failure that plunged the entire New York City into blackout. The city was already down on its luck and was in the midst of a financial crisis, teetering on the edge of bankruptcy and paranoid in the wake of "Son of Sam" murders when this calamity struck. For the impoverished inner city underclass, Christmas came early! A total of 1,616 stores were looted or damaged, more than 1,000 fires were set, plunging the dark streets into chaos. The result was the biggest mass arrest $(3,776)$ in city history, an estimated damage at $\$ 300$ million by looting and vandalism. The accompanying violence was the author's introduction to a mass casualty incident! ${ }^{1}$

\section{The Decade of Crack Cocaine}

The drug epidemic and widened income inequality had maximal impact on large cities such as Los Angeles, New York City, Philadelphia, San Diego, Oakland, Baltimore, Pittsburgh, Washington, D.C., Boston, San Francisco, and Seattle and in states like California, New York, and Pennsylvania.

\section{"America's Uncivil War"}

The inevitable result was a massive escalation of interpersonal violence, keeping the trauma centers and their trauma teams in hectic activity round the clock. Schwab ${ }^{2}$ dubbed it America's uncivil war. Predictably, trauma literature began to be dominated
Department of Surgery, VCU Medical Center, Richmond, Virginia, USA

Corresponding Author: Rao Ivatury, Department of Surgery, VCU Medical Center, Richmond, Virginia, USA, Phone: +1 804651 1575, e-mail: raoivatury@gmail.com

How to cite this article: Ivatury R. Four Decades of Trauma: Blood, Sweat, and Tears. Panam J Trauma Crit Care Emerg Surg 2020;9(1): 85-89.

Source of support: Nil

Conflict of interest: None

by large experience with penetrating trauma. At Lincoln hospital in the South Bronx, it was routine to see 3-7 patients a day with penetrating wounds to the body, often inviting comparisons to Colombia and Brazil. This large experience contributed to the production of The Text Book of Penetrating Trauma. ${ }^{3}$ From Ben Taub hospital in Houston, Feliciano and colleagues ${ }^{4}$ reported on 312 patients with 408 vascular injuries and 48 cardiac injuries in a 2-year period. Two or more vascular or cardiac injuries were present in $34 \%$ of patients. Over $87 \%$ of injuries were secondary to gunshot wounds, stab wounds, or shotgun wounds. In 1989, Mattox et al. ${ }^{5}$ documented an epidemiologic evolution of 5,764 cardiovascular injuries in 4,459 patients and pointed out that the 27 patients per year average of the early 1960s had risen to a new average of 213 patients per year. Comparable series with startling numbers of penetrating trauma of the body became all too frequent at all the major centers of the US. The time was ripe for young surgeons with interest in general surgery and not afraid to work hard to mature in inner city surgical residencies. The wide availability for operative experience and the incredible satisfaction from "miraculous" saves of youthful, though massively injured, bodies provided an intoxicating elixir of a career in trauma, emergency surgery, and critical care. There was no dearth of excitement or challenging scenarios: rambling or tumbling bullets, ${ }^{6}$ the case of the "odd" hole and the missing bullet, foreign bodies in wrong places, and so on.

Each day brought about new and exciting concepts leading to novel therapies pushing the boundaries of survival. Minimally invasive surgery, nonsurgical treatment of major organ injuries, nonsurgical intervention by interventional nonsurgeons, advances 
in resuscitation, damage-control surgery, open-abdomen management, and the secrets of multiorgan dysfunction syndrome are some of the cutting-edge contributions made by visionary pioneers in trauma surgery. These innovations were nicely capsulized in "American Association for the Surgery of Trauma: 75th Anniversary, 1938-2013". ${ }^{7}$ We should be grateful. As Newton had said: we are like dwarfs on the shoulders of giants, so that we can see more than they, and things at a greater distance, not by virtue of any sharpness of sight on our part, or any physical distinction, but because we are carried high and raised up by their giant size. ${ }^{8}$ In all its glory, trauma career had its tearful moments: the author recalls the agony of informing the families about their teenage daughter dying from a motor vehicle crash or of a 3-year-old, an innocent victim of a fatal bullet from a carelessly kept gun.

Trauma and surgical emergencies are universal problems that transcend international borders. The creation and maturation of societies such as the American Association of the Surgery for Trauma (AAST), Eastern Association of Surgery for Trauma (EAST), Western Trauma Association (WTA), and the Panamerican Trauma Society (PTS) by brilliant futurists were just the stimulations needed to germinate the young surgeons of the Americas. Similar stories could be found in Europe [European Society of Trauma and Emergency Surgery (ESTES)], Australia, South Africa, Asia, and others.

The added attraction of trauma was the distinction of the specialty itself: it was the role model for care. It had a regionalized system of multispecialist approach. It was the first discipline to self-assess with honesty, strive to find errors, and implement their correction. The optimal resources' document of the American College of Surgeons Committee on Trauma (ACS-COT) was a landmark living document that was constantly modified, updated, and enhanced. The maturation of trauma centers and trauma systems, constantly improving research and outcomes, and the emphasis on prevention of injuries from guns to automobiles to intimate partners exemplified the exalted nature of trauma as a specialty. ${ }^{7}$ Integrity, risk taking, creativity, vision, and courage became the second nature of our leaders and a successful trauma team. Shackford's chapter on the history of AAST narrates a masterful testimony to the magnitude of these virtues. ${ }^{7}$

As the 1990s rolled on, at the pinnacle of its glory, trauma surgery became a victim of its own success.

\section{How have Trauma and Trauma Surgeons Changed?}

With a regionalized system of care, the workload began to increase enormously. The cases and injuries became more and more complex and severe. The patients were older, with many attendant comorbidities. They were no longer the youthful machine with miraculous abilities of recovery. The excitement of operative surgery became less and less frequent due to the increasing incidence of blunt trauma and a diminution of penetrating trauma, even in the inner city. The advent of nonoperative management in most of the blunt injury cases and expansion of this concept to even penetrating trauma contributed to even further reduction in operative surgery. Surgical specialties, nonsurgical specialties such as interventional endoscopists and radiologists were competing with surgeons for their operative cases. Decades ago, as trauma surgeons we were operating on the whole body, the caseload was large and varied, the work highly stressful but exciting. The hours were long and leisure was limited. But the satisfaction was incredible! Now the trauma service was, for the most part, busy with more and more critical care for the massively injured patient, coordinating the care of specialties like orthopedics and neurosurgery (babysitting for specialties!).

Landmark publications in the 1990s and early 2000s captured the disillusionment of trauma surgeons with their career. ${ }^{9}$ Richardson recently summarized his group's decade-long work in defining the past and the present of trauma surgery as a career. This should be mandatory reading to understand the evolutionary changes in general surgery and trauma. Many other publications ${ }^{9-12}$ reported on the frustration of surgical residents and trauma surgeons with their career. Even though the majority had a good experience and were comfortable with trauma, $63 \%$ did not like to practice trauma. Fifty-four percent felt "burned out" due to the perception that work usually won over family and that they were chronically overworked. In fact, $60 \%$ considered quitting trauma and $75 \%$ considered quitting medicine altogether!

To address this setback, a new specialty, acute care surgery (ACS), to incorporate trauma, critical care, and emergency surgery was created and developed by the AAST. ${ }^{13}$ The EAST, in a position statement, identified the crucial issues to develop a desirable practice that will attract future physicians revolve around the following:

(1) An expanded scope of practice not limited to trauma and surgical critical care, but including both elective and emergency general surgery; (2) a personal and professional lifestyle that allows for predictable and controllable work hours with appropriate support to manage stress; (3) compensation commensurate with the work effort and other high-intensity or high-stress professions. ${ }^{13}$

These were systematically addressed by leading trauma organizations: EAST, AAST, and WTA. Both ACS and a fellowship training in ACS were born. ${ }^{14,15}$

Several tertiary hospitals agree that the ACS teams are now the "general surgeons" with their three pillars of expertise: trauma, emergency general surgery (EGS), and critical care, ${ }^{16-24}$ even though there is tremendous variation in the ACS models: $25 \%$ does EGS alone, $21 \%$ performs EGS and trauma, $17 \%$ EGS and elective surgery, while $30 \%$ perform all three. ${ }^{25}$

A successful ACS system enables the collaboration between acute care surgeons, nonsurgical intensivists, elective general surgeons, and medical staff administration. Indeed, the model is now supported by "specialty surgeons" as well as hospital administrators. ${ }^{16-24,26}$ In the context of finances, several studies documented a positive contribution margin from ACS model. ${ }^{19-21}$ Miller ${ }^{21}$ found that the number of operations by ACS group increased significantly compared with the mean of the 2 years preceding the service creation (1,639 vs 790/year; $p=0.007$ ). Caseload did increase by $23 \%$ in the elective surgery group. They concluded that ACS creation took emergency business from the elective group, but this was replaced with elective cases. The addition of EGS to a trauma service did not compromise trauma patient outcomes. ${ }^{16,26}$ The ACS paradigm is also found to be applicable to smaller community hospitals. ${ }^{22,23}$ Kalina $^{23}$ reported that the model can be successfully implemented and maintained at a nontrauma center with potentially $\$ 2$ million savings in a single year.

Ten years after ACS model implementation, EAST surveyed its members about their career perceptions. ${ }^{24}$ The challenging and exciting activity of ACS was a big incentive. Night call was a negative. Seventy-two percent were satisfied with their career and $92 \%$ were either very happy or somewhat happy. The overall career satisfaction seemed reasonable.

A similar enthusiasm for the acute care surgery model took root in Canada, United Kingdom, Europe, Italy, Israel and Australia. 
Increasingly positive experiences in terms of faster response to emergency department review, shorter time to emergency surgery, and a reduction in hospital length of stay are reported frequently. ${ }^{27}$

\section{Keeping Our Legacy Alive: How to Motivate a New Generation of Surgical Trainees to Consider Trauma as a Career ChOICE?}

The aforementioned surveys of the young surgeons' attitudes toward a career in trauma surgery bring about all the potential negatives that have to be addressed to keep youngsters motivated in our specialty. We must improve "lifestyle" issues: shorten training period, limit work hours, improve quality of work, improve worklife balance, ensure quality time off, and emphasize quality time devoted to family life. Importantly, academic surgeons need to change their attitude, as Moore documented in $1990 .{ }^{28}$ They should address the sinister stress of "balancing time at work vs family". They must ensure that their spouses avoid the "feeling of insignificance, lack of commitment, delayed gratification and lack of intimacy". They should protect their family from feelings of "being married to an academic surgeon is like living with an alcoholic ... except he won't beat you or take the grocery money". A very recent survey ${ }^{29}$ of retired surgeons also emphasized the importance of work-life balance. More than half (52.4\%) of them wished they would have done something differently in the past, especially to have given more time to the family and done a better job of balancing work and family.

If we want our specialty to be attractive, it is most important that senior surgeons take better care of the well-being of their younger colleagues and show them empathy and kindness. As Campbell et al..$^{30}$ pointed out in 2001 , "We have taught residents how to perform surgery but not how to live life as a surgeon". It is time we seniors became a better role model and a mentor in both professional and personal lives. It is time we say more often to our juniors: "I care, let's talk".

Happily, there is evidence that the new kid on the block, the ACS model has become our ally on several fronts in attracting our youngsters: It encourages team work and shift work. It offers a potential for a more balanced work-life environment. It provides more professional satisfaction by exposure to more operative cases than trauma surgery alone will ever provide. In essence, ACS represents the natural maturation of the field of general surgery, and the ACS specialist comes closest to the traditional concept of the true general surgeon. Cherry-Bukowiec and coauthors ${ }^{31}$ documented that the nontrauma emergency surgery service provided ample opportunity for complex decision-making, operative procedures, advanced surgical critical care management, and acute care surgical skills: all excellent for general and ACS residency training. As mentioned earlier, in a survey conducted by the Acute Care Surgery Ad Hoc Committee of EAST, ${ }^{24} 72 \%$ expressed satisfaction with their career profile and $92 \%$ were either very happy or somewhat happy with their career. All evidence supports that ACS is the right answer.

The ACS model appears to have some interest in South American countries as well. New training programs are being set up for residents and fellows. In his 2017 presidential address of PTS, Ordóñe $z^{32}$ reported he, Quintero, and Ricardo Ferrada, trauma and emergency surgeons and professors of the Department of Surgery from del Valle University in Cali along with their mentees
Luis Fernando Pino (Colombia) and Juan Carlos Salamea (Ecuador) have successfully trained a total of 28 fellows: Colombia (20), Ecuador (5), Mexico (1), Chile (1), and Costa Rica (1). The PTS is actively encouraging international fellowships to promote the components of ACS. ${ }^{33,34}$

The trainees' commitment and contribution is also crucial for career satisfaction, as Ball and associates ${ }^{35}$ emphasized, the following is an excellent play book for the young resident:

- "Residency is a 5-year job interview:... arrive on time (or even early!) for every meeting and event, dress appropriately for clinical situations ..., and treat the people around you (nurses, administrative assistants, housekeeping staff, porters, telephone operators, and other hospital staff) with kindness and respect."

- "Successful leadership and teamwork is about relationships: learn to play well in the sandbox: Also remember that being a leader and ensuring strong relationships require effort when you're tired, honesty when it's uncomfortable, and especially integrity when it's difficult."

- "Start thinking about the future now: The surgical world is small, so connections and first-hand testimonials are incredibly important when applying for your fellowship or first job".

- "Controlled ambition and drive is a good thing: "The key concept here, however, is "controlled" drive. Take a breath, think before you speak, come prepared, communicate with a professional and nonpressured style, and use faculty to your academic and clinical benefit."

- "Remember to have fun and enjoy yourself: "It is a privilege to cut, to cure, and to lead .... Although residency is tough and full of daily challenges, we should meet each hurdle with an inner smile and a sense of optimism. Squeeze every bit of life and enjoyment out of each day".

\section{Keeping Our legacy Alive: How to Motivate a New Generation of Medical Students to Consider Surgery as a Career Choice?}

Recently, the Association for Surgical Education conducted a survey of medical students pertaining to surgical life, surgical residency, surgeons as influence, equity, family, and other influences. ${ }^{36}$ Among the 1,365 respondents, men and women disagreed about whether surgeons lead a less well-balanced life ( $68 \%$ and $77 \%$, respectively). A total of $35 \%$ of women were discouraged by a lack of female role models. The study concluded that the decision to have a family was a more significant influence on women than men, but family and lifestyle priorities were also important to male students. Generation and gender are apparently both important influences on career choices. What was depressing in this report was the free-text comments on the students' impression of surgeons: "Only $44 \%$ "surgeons are approachable". "Highly malignant people, with exceptions". "I would not be able to stand these people for a whole career". "Most general surgeons that I have worked with seem like miserable individuals who like to take out their misery on whoever is closest". One female student advised: "Do something to change your programs so people like me who would love to go into surgery and, YES, work hard and can make such a choice without giving up everything else important in their life".

In a commentary on this article, Neumann emphasized the message and suggested: "the perception of our unhappiness speaks 
clearly to their assessment of our lifestyle and their values. We can address issues such as parental leave, child care, and reduced work hours, which would improve lifestyle. We can complain less and show more our basic enjoyment of who we are and what we do". Apparently we, as surgeons, have a lot to learn.

Young medical students recognize intellectual challenge, career opportunities, and technical skills as strengths of surgery. They still, however, worry about lifestyle issues. The power of mentoring by senior faculty on the young minds of students was illustrated by Kozar and colleagues. ${ }^{37}$ Of the 210 first year students, 121 (58\%) students voluntarily attended a brief 1-hour encounter with senior surgeons. From the survey, the following factors were significantly influenced by the intervention: academic opportunities, patient relationships, prestige, and gender distribution became more important. Concern about debt and length of training became less important. The authors concluded that positive encounters with surgeons can favorably influence the perceptions of first year medical students toward a career in surgery. In addition to addressing lifestyle issues, surgeons can and must make a concerted effort to interact with medical students early in their education and foster their interest throughout their career. Mentoring results were very positive also in other initiatives: EAST mentoring program, ${ }^{38}$ Voluntary overnight shadowing of Johns Hopkins University, ${ }^{39}$ the mentoring programs of Cali by Ordóñez, Medellin by Uribe, by Salamea, Panama City by Quiodettis and the Trauma Leagues of Brazil by Fraga.

As with surgical residents, ACS seems to resonate well with medical students in their choice of a surgical career. A recent study ${ }^{40}$ surveyed medical students with interest in surgery as a career asking them to rank factors and experiences influencing career selection. Among 337 responses, $34 \%$ selected trauma/ACS as one of their top three career choices. Factors that were ranked significantly higher by the students interested in T/ACS were related to professional satisfaction. Lifestyle factors received lower emphasis when choosing a surgical career. This appears to be a significant change from surveys in late 1990s described previously that documented the lack of interest in trauma as a career.

\section{Keeping Our Legacy Alive: How to Motivate a New Generation of Nurses to Consider Surgery as a Career Choice?}

Currently there is a changing demographics of nurses: ${ }^{41}$ The age of the average registered nurse (RN) is climbing, and the current ratio of RNs in their 40s and 20s is now 4:1. Burnout was a major reason why nurses leave their current job. Forty percent of nurses in the hospital setting report burnout higher than other healthcare workers. Job dissatisfaction is four times higher than all other employees in the US. Some 34\% of nurses aged 29 and younger and $25.8 \%$ of nurses aged $30-39$ expect to leave the field of emergency nursing within the next 4 years. The Joint Commission did a national nursing engagement survey in $2019 .{ }^{42}$ Of the 2,000 healthcare providers who participated, $56 \%$ said their facility was either slightly or highly ineffective at addressing it.

According to a new advisory from The Joint Commission, Quick Safety, issue 50: "Developing resilience to combat nurse burnout," there are several steps that leaders at healthcare organizations can take to help develop and foster a more resilient environment: Feeling valued professionally, support the use of mentors/role models, develop and practice leadership-empowering behaviors, and create a safe and positive work environment. The Joint Commission says that shared decision-making strengthens the voice of clinical nurses as they collaborate with leaders around optimal staffing plans. Expressing confidence in employees' ability to perform at a high level will help them attain goals. Ensuring that leaders engage in discussions and have a physical presence in the department, will open dialogue and exchange of ideas, as well as providing validation. Open dialogues help provide nursing leaders with a forum to foster best practices, find workable solutions for departmental issues, and teach leadership skills through mentoring sessions.

It is also important that the nursing leaders motivate their staff and "keep the fire alive"43. "What is your vision for your nursing career, and where do you see yourself in 1 year, 5 years? How involved are you in recruiting new nurses? Perhaps someone can catch a dream from your recollection of an inspiring story. Perhaps a window may open to a career choice just because of you".

In the words of Confucius, "Tell me, and I will forget, show me and I may remember, involve me and I will understand".

\section{SUMmaRY}

In summary, the new specialty of acute care surgery is a welcome development and, thankfully, effective in keeping our legacy alive. In his 2018 PTS presidential address, ${ }^{44}$ Rizoli concluded "To raise a child takes a village," the same can be said about caring for a single injured patient, it requires a "village" of many professionals... "In my opinion, people have had a larger impact in improving trauma care than science."

It has been a tremendous honor to be in the team caring for the critically ill and a true blessing to have had the opportunity to cultivate the next generation of the "people in the village". It has been a memorable ride of blood, sweat, and tears (of Joy!).

\section{References}

1. https://gothamist.com/arts-entertainment/40-years-laterremembering-the-infamous-blackout-of-1977. Accessed March 9 2020.

2. Schwab CW. Violence: America's uncivil war--presidential address, sixth scientific assembly of the eastern association for the surgery of trauma. J Trauma 1993;35(5):657-665. DOI: 10.1097/00005373199311000-00001.

3. Ivatury RR, Cayten CG. The Textbook of Penetrating Trauma The Textbook of Penetrating Trauma. Philadelphia: Williams \& Wilkins; 1996.

4. Feliciano DV, Bitondo CG, Mattox KL, et al. Civilian trauma in the 1980 s. A 1-year experience with 456 vascular and cardiac injuries. Ann Surg 1984;199(6):717-724. DOI: 10.1097/00000658-198406000-00010.

5. Mattox KL, Feliciano DV, Burch J, et al. Five thousand seven hundred sixty cardiovascular injuries in 4459 patients. Epidemiologic evolution 1958 to 1987. Ann Surg 1989;209(6):698-707. DOI: 10.1097/00000658$198906000-00007$.

6. Ivatury RR, Rohman M. The case of the rambling bullet. NY State J Med 1984;84(3 Pt 1):108.

7. American Association For The Surgery Of Trauma 75th anniversary 1938-2013.

8. Newton I. "Letter from sir Isaac newton to Robert Hooke". Historical society of Pennsylvania. Wikipedia Accessed 2020.

9. Richardson JD. Confessions of a dinosaur. J Trauma Acute Care Surg 2019;83(1):7-10. DOI: 10.1097/TA.0000000000001509.

10. Esposito TJ. Trauma and trauma care systems: In the throes of an identity crisis. A plea for changing the vernacular and the mind-set. Arch Surg 2000;135(6):716-718. DOI: 10.1001/archsurg.135.6.716, discussion 719. 
11. Moore EE. Trauma surgery: is it time for a facelift? Ann Surg 2004;240(3):563-564. DOI: 10.1097/01.sla.0000138627.41723.ea.

12. Esposito TJ, Leon L, Jurkovitch GJ. The shape of things to come: Results from a national survey of trauma surgeons on issues concerning their future. J Trauma 2006;60(1):8-16. DOI: 10.1097/01. ta.0000197425.87092.d5.

13. Rotondo MF, Esposito TJ, Reilly PM, et al. The position of the eastern association for the surgery of trauma on the future of trauma surgery. J Trauma 2005;59(1):77-79. DOI: 10.1097/01.ta.0000171848.22633.c0.

14. Committee to develop the reorganized specialty of trauma surgical critical care and emergency surgery. Acute care surgery: Trauma, critical care, and emergency surgery. J Trauma 2005;58(3):614-616. DOI: 10.1097/01.ta.0000159347.03278.e1.

15. Britt LD. Acute care surgery: is it time for a victory lap? J Trauma 2016;80(1):8-15. DOI: 10.1097/TA.0000000000000895.

16. Ciesla DJ, Cha JY, Smith, et al. Implementation of an acute care surgery service at an academic trauma center. Am J Surg 2011;202(6):779-785. DOI: 10.1016/j.amjsurg.2011.06.046.

17. Tisherman SA, Ivy ME, Frangos SG, et al. Acute care surgery survey: opinions of surgeons about a new training paradigm. Arch Surg 2011;146(1):101-106. DOI: 10.1001/archsurg.2010.289.

18. Privette AR, Evans AE, Moyer JC, et al. Beyond emergency surgery: redefining acute care surgery. J Surg Res 2015;196(1):166-171. DOI: 10.1016/j.jss.2014.11.012.

19. Procter $L$, Bernard AC, Korosec RL, et al. An acute care surgery service generates a positive contribution margin in an appropriately staffed hospital. J Am Coll Surg 2013;216(2):298-301. DOI: 10.1016/j. jamcollsurg.2012.09.020

20. Alexander MS, Nelson C, Coughenour J. Acute care surgery practice model: targeted growth for fiscal success. Surgery 2013;154(4):867872. DOI: 10.1016/j.surg.2013.07.012.

21. Miller PR, Wildman EA, Chang MC, et al. Acute care surgery: Impact on practice and economics of elective surgeons. J Am Coll Surg 2012(4):214-531. DOI: 10.1016/j.jamcollsurg.2011.12.045.

22. O'Mara MS, Scherer L, Wisner D, et al. Sustainability and success of the acute care surgery model in the nontrauma setting. J Am Coll Surg 2014;219(1):90-100. DOI: 10.1016/j.jamcollsurg.2014.02.022.

23. Kalina M. Implementation of an acute care surgery service in a community hospital: impact on hospital efficiency and patient outcomes. Am Surg 2016;82(1):79-84.

24. Lissauer ME, Schulze R, May A, et al. Update on the status and future of acute care surgery: 10 years later. J Trauma Acute Care Surg 2014;76(6):1462-1466. DOI: 10.1097/TA.0000000000000226.

25. Santry HP, Madore JC, Collins CE, et al. Variations in the implementation of acute care surgery: results from a national survey of universityaffiliated hospitals. J Trauma Acute Care Surg 2015;78(1):60-67. DOI: 10.1097/TA.0000000000000492.

26. Qureshi A, Smith A, Wright F, et al. The impact of an acute care emergency surgical service on timely surgical decision making and emergency department overcrowding. J Am Coll Surg 2011;213(2):284-293. DOI: 10.1016/j.jamcollsurg.2011.04.020.

27. Ivatury R, Catena F. Acute care surgery around the world. Future Prespectives. In: Acute Care Surgery Handbook Di Saverio S Switzerland: Springer International Publishing; 2017.
28. Moore EE. Swimming with the sharks-without the family being eaten alive. Surgery 1990;108(2):125-138.

29. Stolarski A, Moseley JM, O'Neal P, et al. Retired surgeons' reflections on their careers. JAMA Surg, Published online January 22 2020(4). DOI: 10.1001/jamasurg.2019.5476.

30. Campbell DAJr, Sonnad SS, Eckhauser FE, et al. Burnout among american surgeons. Surgery 2001;130(4):696-702. DOI: 10.1067/ msy.2001.116676.

31. Cherry-Bukowiec JR, Miller BS, Doherty GM, et al. Nontrauma emergency surgery: optimal case mix for general surgery and acute care surgery training. J Trauma 2011;71(5):1422-1426. DOI: 10.1097/ TA.0b013e318232ced1.

32. Ordóñez CA. The trauma and emergency surgeon: past, present and future. Panam J Trauma Crit Care Emerg Surg 2019;8(1):1-11. DOI: 10.5005/jp-journals-10030-1230.

33. Ivatury RR, Aboutanos M. Panamerican trauma society: The first three decades. J Trauma Acute Care Surg 2017;82(5):966-973. DOI: 10.1097/TA.0000000000001393.

34. Ferrada $P, A$ boutanos $M B$, Ivatury RR. International surgical rotations: a prodigious personal and professional maturation. Am Surg 2015;81(5):E230-E231.

35. Ball CG, Grondin SC, Dixon E, et al. Five things they don't teach you in medical school. J Can Chir 2016;59(5):296-298. DOI: 10.1503/ cjs.006616.

36. Sanfey HA, Saalwachter-Schulman AR, Nyhof-Young JM, et al. Influences on medical student career choice gender or generation? Arch Surg 2006;141(11):1086-1094. DOI: 10.1001/archsurg.141. 11.1086.

37. Kozar RA, Lucci A, Miller CC, et al. Brief intervention by surgeons can influence students toward a career in surgery. J Surg Res 2003;111(1):166-169. DOI: 10.1016/s0022-4804(03) 00104-5.

38. https://www.east.org/career-management/mentoring/eastmentoring-program (accessed March 14, 2020).

39. Stroh DA, Ray-Mazumder N, Norman JA, et al. Influencing medical student education via a Voluntary shadowing program for trauma and acute care surgery. JAMA Surg 2013;148(10):968-970. DOI: 10.1001/jamasurg.2013.363.

40. Moore PK, Grant AR, Tello TL, et al. Future of acute care surgery: a perspective from the next generation. J Trauma Acute Care Surg 2012;72(1):94-99. DOI: 10.1097/TA.0b013e31823b990a.

41. Schumaker J, Taylor W, McGonigle T. The emergency, trauma, and transport nursing workforce: highlights of a benchmark 2019 survey. Nurs Manage 2019;50(12):20-32. DOI: 10.1097/01. NUMA.0000605152.42445.4b

42. The Joint Commission tackels nurse burnout. https://www. healthleadersmedia.com/nursing/joint-commission-tackles-nurseburnout Accessed March 14, 2020.

43. Bennett VJ. Keeping the fire alive. J Trauma Nurs 2005;12(1):5. DOI: 10.1097/00043860-200512010-00001.

44. Rizoli S. Presidential address: science, people,and justice. Vision of the Panamerican trauma society. Panam J Trauma Crit Care Emerg Surg 2019;8(1):12-18. DOI: 10.5005/jp-journals-100301231. 